\title{
Low-Dose Insecticide Combinations for Colorado Potato Beetle Control
}

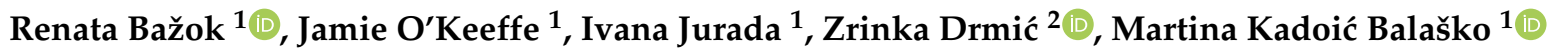 \\ and Maja Čačija ${ }^{1, * \mathbb{C}}$
}

1 Department of Agricultural Zoology, Faculty of Agriculture, University of Zagreb, Svetošimunska cesta 25, 10000 Zagreb, Croatia; rbazok@agr.hr (R.B.); okeeffejamie88@gmail.com (J.O.); ijurada30494@gmail.com (I.J.); mbalasko@agr.hr (M.K.B.)

2 Centre for Plant Protection, Croatian Agency for Agriculture and Food, Vinkovačka cesta 63c, 31000 Osijek, Croatia; zrinka.drmic@hapih.hr

* Correspondence: mcacija@agr.hr

Citation: Bažok, R.; O’Keeffe, J.; Jurada, I.; Drmić, Z.; Kadoić Balaško, M.; Čačija, M. Low-Dose Insecticide Combinations for Colorado Potato Beetle Control. Agriculture 2021, 11, 1181. https://doi.org/10.3390/ agriculture11121181

Academic Editor: Azucena González Coloma

Received: 7 October 2021

Accepted: 18 November 2021

Published: 23 November 2021

Publisher's Note: MDPI stays neutral with regard to jurisdictional claims in published maps and institutional affiliations.

Copyright: (c) 2021 by the authors. Licensee MDPI, Basel, Switzerland. This article is an open access article distributed under the terms and conditions of the Creative Commons Attribution (CC BY) license (https:// creativecommons.org/licenses/by/ $4.0 /)$.

\begin{abstract}
Colorado potato beetle (CPB) is the most notorious and problematic insect defoliator pest of potato. It is well known for its ability to develop resistance to chemical insecticides, so novel treatment methods must be developed. A possible solution is the application of newer groups of insecticides (biotechnical and biological insecticides) which are more selective and to which resistance has not yet been recorded. This work investigated the use of ecologically acceptable insecticide treatments: azadirachtin, spinosad and spinetoram, and their combinations against CPB larvae in laboratory and field conditions. Reduced dosing and combinational treatments were used to determine if effective protection against $\mathrm{CPB}$ could be achieved while also improving economic results. Our results from laboratory trials showed that combinations of low-dose azadirachtin (25\%) and low-dose spinetoram (5\%) are suitable for use in CPB integrated pest management. The results of the field trial showed that the use of 50\% reduced dosage of spinosad and spinetoram resulted in high efficacy (89-99\%) and can be recommended as a treatment method that provides effective control of $\mathrm{CPB}$, improved economic results, and a positive environmental impact. Based on the advantages that these treatments offer compared to chemical insecticides, further work is recommended to determine if these combinational treatments used in other dosages or in combinations with some other ecologically acceptable insecticides can provide satisfactory control of CPB.
\end{abstract}

Keywords: biological control; Leptinotarsa decemlineata Say; insecticide resistance management; reduced-risk insecticides; integrated pest management (IPM)

\section{Introduction}

Potato production represents the fifth largest agricultural crop worldwide [1]. For centuries, potatoes were grown and consumed primarily in North America and Europe, but in the last 30 years, the area of cultivation has expanded dramatically to areas such as Asia, Latin America, and Africa. With this increased production range comes increased potato consumption. In just 20 years (1991-2011), worldwide potato consumption increased from 27.35 to $34.64 \mathrm{~kg} /$ capita/year, after several decades of hovering around $27 \mathrm{~kg} /$ capita/year [1]. This could be in large part due to the expanded growing range of potatoes in the developing world. This increased consumption is seen as a good thing by many, the FAO (2008) [2] states "the potato produces more nutritious food more quickly, on less land, and in harsher climates than any other major crop". In many places where potato is grown, yields are threatened by the infamous insect pest: the Colorado potato beetle.

The Colorado potato beetle (CPB, Leptinotarsa decemlineata (Say, 1824)) (Coleoptera: Chrysomelidae) has a long story as an agricultural menace. With over 150 years of history as a pest of potato crops, it is considered the most important and notorious insect defoliator of the potato [3-7]. With the increased range of potato production worldwide comes the 
increased potential for $\mathrm{CPB}$ to expand its range as well. $\mathrm{CPB}$ has a remarkable plasticity and is able to adapt to a number of biotic and abiotic factors to a degree rarely seen in the world of agricultural insect pests. CPB made quick work out of expanding and colonizing the areas historically known for potato production and it is only logical to expect further expansion into newer growing regions $[8,9]$.

$\mathrm{CPB}$ has a long history of control measures including cultural, physical, mechanical and biological means, even still, synthetic insecticidal control has always been the preferred control measure by growers [7]. Due to early success with chemical control methods, most growers turn exclusively to broad-spectrum, synthetic insecticides to protect their potato crop [3]. This indiscriminate use of synthetic insecticides has led to resistance problems with CPB. CPB populations have developed resistance to nearly every class of insecticide on the market, leaving some growers with few options for control [10]. The principle of Integrated Pest Management (IPM) has been proposed as a means to combat $\mathrm{CPB}$ and reduce resistance problems. IPM uses a multi-pronged approach to deal with pest populations and looks to chemical intervention as a final option. IPM uses all the tools in the plant protection tool box including cultural, physical, mechanical and biological control methods. Implementing IPM into potato production can reduce financial inputs (in the form of fewer insecticides), slow insecticidal resistance development as well as lessen the impacts of synthetic, broad-spectrum insecticides on the environment and biodiversity. We should no longer rely solely on synthetic insecticides to solve the problem of CPB. New and novel treatments need to be explored and integrated into IPM strategies.

Due to their ecotoxicological characteristics some insecticides are more suitable for CPB control. Those environmentally friendly insecticides are Bacillus thuringiensis var. tenebrionis based insecticides, neem extract, natural pyrethrin, spinosad and spinetoram [11]. The use of combinations of insecticides with different modes of action has been advocated for years as the tool for slowing down resistance development $[12,13]$. Kovačević [14] suggested the addition of sub-lethal doses of chemical insecticides to biological insecticides to improve their efficacy. Others [12] pointed out that combinations of environmentally friendly insecticides with classical insecticides at lower doses can lead to ecological, biological and economic benefits, and additionally, Thabet et al. [15] recommended nanopesticides as an alternative to conventional insecticides.

When combining insecticides with different mechanisms of action, it is possible that the effect of the combination is not the sum of the action of the components in the mixture, but that it is the result of their interaction [16]. Some interactions have a positive effect, while others have a negative effect on the final effect on the pest. Synergism may be defined as the interaction or cooperation of two or more substances to produce a combined effect greater than the sum of their individual effects [17]. On the other hand, antagonism is a phenomenon where two or more agents in combination have an overall effect that is less than the sum of their individual effects [17]. If the effect of a combination is greater than the effect of the more active component, but less than the sum of the individual effects of the component, such an interaction is called independent synergism [17]. Before applying insecticide combinations in the field, it is necessary to investigate the interactions and determine the possible joint effect.

We hypothesized that the use of ecologically acceptable insecticides, azadirachtin, spinosad and spinetoram, applied at reduced doses and in combination at reduced dosing, could result in the same efficacy against CPB as the manufacturer recommended full doses. Roush [18] first found that under certain conditions mixtures can delay the development of resistance more effectively than sequences or rotations. According to Curtis [19], if resistance to each compound is independent and initially rare, the associated probability of resistance to both compounds is extremely rare. The use of organophosphate and pyrethroid mixtures in West Africa to spray cotton has prevented the development of pyrethroid resistance in the cotton bollworm for more than 20 years [20]. More recently, Helps et al. [21] suggest that the effective life of insecticide modes of action could be increased by reducing the insecticide dose below the maximum allowable level, if this can 
be done without compromising effective control. This would reduce insecticide use and improve economic outcomes while slowing the development of resistance. To reduce the negative impact of insecticides, in this study, we used insecticides that are more environmentally friendly. This research aimed to establish: (I) the nature of the interaction between spinosad and azadirachtin, and spinetoram and azadirachtin in terms of effect on CPB feeding capacity and mortality; (II) the field efficacy of reduced dosing and combinations of ecologically acceptable insecticides on CPB; and (III) the residual activity of investigated combinations and evaluate the most acceptable one.

\section{Materials and Methods}

\subsection{Laboratory Trial}

For the laboratory experiment, $660 \mathrm{CPB}$ larvae of the early (2nd and 3rd) developmental stage as well as potato leaves were collected from an untreated potato field at the Maksimir experimental station, Faculty of Agriculture, Zagreb, Croatia (field coordinates: $45^{\circ} 49^{\prime} 45.8^{\prime \prime} \mathrm{N} 16^{\circ} 02^{\prime} 01.5^{\prime \prime} \mathrm{E}$ ). The larvae and the leaves were collected on $14 \mathrm{June} 2019$ and the experiment was set up on 17 June 2019. The experiment was conducted according to an internationally accepted method for proving insect resistance, the IRAC Susceptibility Test Method No: 007 [13]. In experiments three commercial products, Laser 240 SC (based on spinosad, produced by Dow AgroSciences, Vienna, Austria), Radiant (based on spinetoram, produced by Dow AgroSciences, Vienna, Austria) and NeemAzal T/S (produced by Trifolio-M GmbH, Lahnau, Germany) were used. The experiment included ten insecticide treatments and an untreated control (Table 1).

Table 1. Insecticidal treatments used against Colorado potato beetle larvae in the laboratory trial, Zagreb, 2019.

\begin{tabular}{|c|c|c|c|c|c|}
\hline $\begin{array}{l}\text { Treatment } \\
\text { No. }\end{array}$ & Insecticide Product & $\begin{array}{l}\text { Active Ingredient (a.i.) } \\
\text { and a.i. Content in } \\
\text { Product (g/L) }\end{array}$ & $\begin{array}{l}\text { Insecticide Dose } \\
\text { (L/ha) }\end{array}$ & Dose of a.i. (g/ha) & $\begin{array}{c}\text { Percentage of Full } \\
\text { Dose }(\%)\end{array}$ \\
\hline 1 & Laser 240 SC & spinosad 240 & 0.030 & 7.20 & 20 \\
\hline 2 & Laser 240 SC & spinosad 240 & 0.015 & 3.60 & 10 \\
\hline 3 & Laser 240 SC & spinosad 240 & 0.0075 & 1.80 & 5 \\
\hline 4 & Radiant & spinetoram 120 & 0.100 & 12.00 & 30 \\
\hline 5 & Radiant & spinetoram 120 & 0.050 & 6.00 & 15 \\
\hline 6 & Radiant & spinetoram 120 & 0.025 & 3.00 & 7.5 \\
\hline 7 & NeemAzal T/S & azadirachtin 10 & 1.250 & 12.50 & 50 \\
\hline 8 & NeemAzal T/S & azadirachtin 10 & 0.625 & 6.25 & 25 \\
\hline 9 & $\begin{array}{c}\text { NeemAzal T/S + } \\
\text { Laser } 240 \text { SC }\end{array}$ & $\begin{array}{l}\text { azadirachtin } 10+ \\
\text { spinosad } 240\end{array}$ & $0.625+0.0075$ & $6.25+1.80$ & $25+5$ \\
\hline 10 & $\begin{array}{c}\text { NeemAzal T/S + } \\
\text { Radiant }\end{array}$ & $\begin{array}{l}\text { azadirachtin } 10+ \\
\text { spinetoram } 120\end{array}$ & $0.625+0.025$ & $12.5+3.00$ & $25+7.5$ \\
\hline 11 & Untreated control & N/A & $\mathrm{N} / \mathrm{A}$ & $\mathrm{N} / \mathrm{A}$ & $\mathrm{N} / \mathrm{A}$ \\
\hline
\end{tabular}

For each treatment, a dilution of a certain amount of product was prepared in such a way that the dose was converted into a concentration assuming the consumption of $1000 \mathrm{~L}$ of water/ha. For each treatment, several potato leaves were dipped and held for five seconds in the prepared solution. The control leaves were dipped in clean water. The leaves were then placed to dry in labeled water bottles for several hours.

Before setting up the experiment, 110 petri dishes were prepared on the bottom of which a filter paper previously soaked in water was placed. Each treatment was repeated 10 times. Before placing one leaf in each petri dish, the leaf area was measured using the LeafByte application. After that, five CPB larvae (2nd and 3rd instar) were added to each petri dish.

Petri dishes were kept in laboratory at room conditions (temperature of $25 \pm 1^{\circ} \mathrm{C}$ and $60 \pm 5 \%$ relative humidity, natural exchange of day and night, respectively 16:8 h (L:D)) in open transparent plastic containers, during the whole experiment. Every $24 \mathrm{~h}$ over a period of four days, in each petri dish the number of dead larvae was established. The treated leaf 
was removed, photographed with the LeafByte application to measure the leaf area and then returned to the petri dish. If the leaf was significantly destroyed it was replaced with a new one with a previously measured leaf area.

\subsection{Field Trial}

The field trial took place in 2019 at the experimental station Maksimir at the Faculty of Agriculture in Zagreb, on a field of $800 \mathrm{~m}^{2}$ (field coordinates: $45^{\circ} 49^{\prime} 45.8^{\prime \prime} \mathrm{N} 16^{\circ} 02^{\prime} 01.5^{\prime \prime} \mathrm{E}$ ). The field was planted on 3 April 2019 in 20 rows of Tiamo variety potatoes, approximately $55 \mathrm{~m}$ long. The planting depth and density was as follows: $15 \mathrm{~cm}$ deep, $30 \mathrm{~cm}$ in-row spacing and $50 \mathrm{~cm}$ inter-row spacing. The soil type is slightly acidic clay soil. The field was previously planted with maize in 2016 and 2017 and was fallow in 2018. Potatoes were never grown on this plot before. A few days prior to planting, fertilization was conducted with a mix of NPK 7-20-30 (100 kg) and NPK 15-15-15 $(50 \mathrm{~kg})$ being used. Approximately 10-14 days after planting, herbicide treatment was conducted using Sencor SC 600 (produced by Bayer, Leverkusen, Germany) in a dose of $0.6 \mathrm{~L} / \mathrm{ha}$ and a second herbicide treatment of Basagran 480 (produced by BASF SE, Ludwigshafen, Germany) in a dose of $2.0 \mathrm{~L} /$ ha was conducted on 8 May 2019. The field was maintained until early June.

Due to heavy rains throughout May, the trial start date was delayed by several weeks. The study was designed following EPPO guidelines [22]. The study field was divided into four blocks (I, II, III, and IV), each containing four rows ( $3 \mathrm{~m}$ wide) while two rows were left as a border on each side (20 rows in total). Inside each block 11 treatments were randomized using a randomized block design, which is detailed in Table 2. Dosing rates were carried out at varying amounts of $100 \%, 50 \%$ and $10 \%$ of dosage recommended by manufacturers. The length of each plot was $4 \mathrm{~m}$, with each plot covering $12 \mathrm{~m}^{2}$ and there were four replications per treatment $\left(48 \mathrm{~m}^{2}\right.$ total per treatment).

Table 2. Insecticidal treatments used against Colorado potato beetle larvae in the field trial, Zagreb, 2019.

\begin{tabular}{|c|c|c|c|c|c|}
\hline $\begin{array}{l}\text { Treatment } \\
\text { No. }\end{array}$ & Insecticide Product & $\begin{array}{l}\text { Active Ingredient (a.i.) } \\
\text { and a.i. Content in } \\
\text { Product }(\mathrm{g} / \mathrm{L})\end{array}$ & $\begin{array}{l}\text { Insecticide Dose } \\
\text { (L/ha) }\end{array}$ & Dose of a.i. (g/ha) & $\begin{array}{c}\text { Percentage of Full } \\
\text { Dose }(\%)\end{array}$ \\
\hline 1 & Laser 240 SC & spinosad 240 & 0.15 & 36.0 & 100 \\
\hline 2 & Laser 240 SC & spinosad 240 & 0.075 & 18.0 & 50 \\
\hline 3 & Laser 240 SC & spinosad 240 & 0.015 & 3.6 & 10 \\
\hline 4 & Radiant & spinetoram 120 & 0.30 & 36.0 & 100 \\
\hline 5 & Radiant & spinetoram 120 & 0.15 & 18.0 & 50 \\
\hline 6 & Radiant & spinetoram 120 & 0.03 & 3.6 & 10 \\
\hline 7 & NeemAzal T/S & azadirachtin & 2.50 & 25.0 & 100 \\
\hline 8 & NeemAzal T/S & azadirachtin & 1.25 & 12.5 & 50 \\
\hline 9 & $\begin{array}{c}\text { NeemAzal T/S + } \\
\text { Laser } 240 \text { SC }\end{array}$ & $\begin{array}{l}\text { azadirachtin } 10+ \\
\quad \text { spinosad } 240\end{array}$ & $1.25+0.015$ & $12.5+3.6$ & $50+10$ \\
\hline 10 & $\begin{array}{c}\text { NeemAzal T/S + } \\
\text { Radiant }\end{array}$ & $\begin{array}{l}\text { azadirachtin } 10+ \\
\text { spinetoram } 120\end{array}$ & $1.25+0.03$ & $12.5+3.6$ & $50+10$ \\
\hline 11 & Untreated control & $\mathrm{N} / \mathrm{A}$ & $\mathrm{N} / \mathrm{A}$ & $\mathrm{N} / \mathrm{A}$ & $\mathrm{N} / \mathrm{A}$ \\
\hline
\end{tabular}

CPB larvae were counted the day before insecticidal spraying, 5 June 2019. Plant infestation varied among plots from plants with low infestation to plants with heavy infestation. Therefore, CPB larvae were counted and plants were marked until 100 larvae were identified so that the baseline was 100 larvae for each plot. Plants were marked using plastic signal tape ( $4 \mathrm{~cm}$ wide) and was done in such a way that the plant was wrapped around with the tape, which resulted in the diameter of the plant being reduced and the marked plants not touching neighboring plants to prevent larvae from migrating between neighboring plants.

Insecticidal treatment was carried out on 6 June 2019, when CPB larvae were present, according to the randomized plot determined in advance. Spraying was conducted using a 
high-pressure sprayer Euro-Pulvé (Aspach, France), delivering $300 \mathrm{~L} /$ ha. After spraying, CPB larvae on previously marked plants were recounted on days 2, 5, 7, 10, 14 and 21.

\subsection{Statistical Analysis}

Based on the mortality of larvae in the laboratory trial, the efficacy was calculated by using Schneider-Orelli formula [23].

$$
\text { Corrected mortality } \%=\frac{\text { Mortality } \% \text { in treatment }- \text { Mortality } \% \text { in the control }}{100-\text { Mortality } \% \text { in control }} * 100
$$

In addition to that, for each day and each repetition the eaten leaf area was calculated as the difference in leaf area the day before the evaluation and on the day of the evaluation. The efficacy of different treatments in preserving leaf area from larval consumption was calculated according to Abbott formula [24]. Data on consumed leaf area and efficacies were processed by ANOVA using the statistical software ARM $9^{\circledR}$ [25]. Mean data were ranked using the Tukey's HSD Test to determine the differences in leaf area consumption and efficacies between treatments.

In the field trial, number of larvae per treatment was analyzed using ANOVA. Tukey's HSD Test was used to determine the differences among the treatments (including untreated control) between the mean values of larvae per treatment. Based on average number of larvae per replication and untreated control the efficacies of insecticides were calculated by using the Abbott formula [24]. Calculated efficacies were analyzed using ANOVA, and Tukey's HSD Test was used to determine the differences among the treatments. Results were analyzed by the use of ARM $9^{\circledR}$ software [25].

For insecticide combinations in both laboratory and field trial, the expected efficacy was calculated under the assumption of independent synergism according to the formula used by Salama et al. (1984) [26]:

$$
\mathrm{E}=\mathrm{O}_{\mathrm{b}}+\mathrm{O}_{\mathrm{s}}\left(1-\mathrm{O}_{\mathrm{b}} / 100\right)
$$

where $\mathrm{E}$ is the expected efficacy of the combination under the assumption of independent synergism and $\mathrm{O}_{\mathrm{b}}$ and $\mathrm{O}_{\mathrm{s}}$ are efficacies of individual components (in the same doses). The achieved efficacy of the combination was tested by $\chi^{2}$ test using the formula:

$$
\chi^{2}=\left(\mathrm{O}_{\mathrm{c}}-\mathrm{E}\right)^{2} / \mathrm{E},
$$

where $\mathrm{O}_{c}$ is the achieved efficacy of the combination and $\mathrm{E}$ is the expected efficacy of the combination. The obtained results of the $\chi^{2}$ test were compared with the critical $\chi^{2}$ value $(\mathrm{df}=1, p=0.05)=3.84$. If the obtained $\chi^{2}$ did not differ significantly from the tabular one, we concluded that the effect of the combination is an independent synergism. In the case that the obtained $\chi^{2}$ differed from the tabular one, we concluded that the effect of the components is synergism or antagonism, depending on whether the achieved efficacy is higher or lower than expected [26].

\section{Results and Discussion}

\subsection{Laboratory Trial}

Due to the low doses of insecticides used in the laboratory study, a low initial efficacy against CPB was found. However, in the last two days of the trial the efficacies increased. Thus, doses of only $10 \%$ and $30 \%$ of spinosad and spinetoram on the 4 th day after treatment reached efficacy of about $90 \%$ (Table 3), which is, given the very low applied doses, very high efficacy. Other research also reported on such a good effect of low doses and high biological activity of spinosad [12]. Some authors explain the extremely high efficacy of reduced doses of insecticides in laboratory experiments by the absence of external factors that affect the pests we control, and by the fact that the application of insecticides in the laboratory experiment is much more precise $[26,27]$. Higher efficiency of low doses of 
insecticides in the laboratory indicates that there is a large loss of active substance in the field due to the action of environmental factors [28]. The variability in efficacy found in the experiment was due to a number of factors such as the age and diversity of the larval population and much higher temperature conditions during the experiment.

Table 3. Efficacy (\%) of insecticides ( \pm SE) on Colorado potato beetle larvae over the course of the laboratory trial.

\begin{tabular}{|c|c|c|c|c|c|}
\hline Active Ingredient (a.i.) & $\begin{array}{l}\text { Dose a.i. } \\
\text { (g/ha) }\end{array}$ & $24 \mathrm{~h}^{1}$ & $48 \mathrm{~h}^{2}$ & $72 \mathrm{~h}$ & $96 h^{3}$ \\
\hline spinosad & 7.2 & $2.58 \pm 15.27 \mathrm{bc}$ & $28.00 \pm 16.87 \mathrm{bcd}$ & $71.11 \pm 18.29 \mathrm{ab}$ & $92.92 \pm 16.27 \mathrm{a}$ \\
\hline spinosad & 3.6 & $10.04 \pm 16.63 \mathrm{ab}$ & $58.00 \pm 23.94 \mathrm{a}$ & $84.44 \pm 15.00 \mathrm{a}$ & $98.84 \pm 13.01 \mathrm{a}$ \\
\hline spinosad & 1.8 & $0.00 \pm 0.00 \mathrm{c}$ & $6.00 \pm 9.66 \mathrm{~d}$ & $21.11 \pm 19.91 \mathrm{~d}$ & $18.66 \pm 19.02 \mathrm{~d}$ \\
\hline spinetoram & 12.0 & $5.28 \pm 14.00 \mathrm{abc}$ & $32.00 \pm 16.87 \mathrm{a}-\mathrm{d}$ & $80.00 \pm 22.10 \mathrm{a}$ & $91.46 \pm 18.51 \mathrm{a}$ \\
\hline spinetoram & 6.0 & $23.30 \pm 13.16 \mathrm{a}$ & $52.00 \pm 30.11 \mathrm{ab}$ & $66.70 \pm 21.60 \mathrm{abc}$ & $86.39 \pm 19.58 \mathrm{ab}$ \\
\hline spinetoram & 3.0 & $1.92 \pm 12.83 \mathrm{bc}$ & $30.00 \pm 14.14 \mathrm{bcd}$ & $48.89 \pm 15.00 \mathrm{bcd}$ & $55.38 \pm 16.53 \mathrm{bcd}$ \\
\hline azadirachtin & 12.5 & $19.50 \pm 16.04 \mathrm{ab}$ & $42.00 \pm 22.01 \mathrm{abc}$ & $62.22 \pm 27.81 \mathrm{abc}$ & $73.93 \pm 26.61 \mathrm{abc}$ \\
\hline azadirachtin & 6.25 & $23.47 \pm 11.97 \mathrm{a}$ & $38.00 \pm 11.35 \mathrm{abc}$ & $60.00 \pm 22.95 \mathrm{abc}$ & $92.92 \pm 16.27 \mathrm{a}$ \\
\hline azadirachtin + spinosad & $6.25+1.8$ & $3.40 \pm 13.72 \mathrm{abc}$ & $16.00 \pm 15.78 \mathrm{~cd}$ & $37.78 \pm 17.53 \mathrm{~cd}$ & $41.57 \pm 12.58 \mathrm{~cd}$ \\
\hline $\begin{array}{l}\text { azadirachtin }+ \\
\text { spinetoram }\end{array}$ & $6.25+3.0$ & $23.30 \pm 13.16 \mathrm{a}$ & $48.00 \pm 16.87 \mathrm{ab}$ & $73.33 \pm 17.53 \mathrm{ab}$ & $95.43 \pm 15.94 \mathrm{a}$ \\
\hline \multicolumn{2}{|c|}{ Tukey's HSD $p=0.05$} & 18.308 & 27.099 & 30.134 & 25.311 \\
\hline \multicolumn{2}{|c|}{ Treatment F } & 6.659 & 7.463 & 9.000 & 12.249 \\
\hline \multicolumn{2}{|c|}{ Treatment Prob (F) } & 0.0001 & 0.0001 & 0.0001 & 0.0001 \\
\hline
\end{tabular}

${ }^{1}$ Prior to analysis, the data were transformed using arc.sin $\sqrt{ } x$ transformation. ${ }^{2}$ Prior to analysis, the data were transformed using $\sqrt{ } x+0.5$ transformation. ${ }^{3}$ Prior to analysis, the data were transformed using $\log (x+1)$ transformation. Means followed by same letter in the same column do not significantly differ $(p=0.05$, Tukey's HSD Test).

The results of this study showed that, of the environmentally friendly insecticides, the highest efficiency on CPB larvae was achieved by spinosad applied in $10 \%$ and $20 \%$ of the full recommended doses (Table 3). In laboratory studies conducted in 2001 and 2002, the efficacy of spinosad on CPB on the 4th day after treatment was similar and amounted to $96 \%$ [28]. The efficacy of the lowest, $5 \%$ dose of spinosad (1.8 $\mathrm{g}$ a.i. /ha) was the lowest throughout the experiment, and the maximum efficacy four days after treatment was $18.66 \%$.

Although according to some reports, spinetoram should show a faster and stronger action in pest control in comparison to spinosad [29], in the conducted research this did not happen. High efficacy was achieved (Table 3), but with slightly lower larval mortality. The dose of $12 \mathrm{~g}$ a.i. / ha ( $30 \%$ of the full dose) achieved efficacy of $80 \%$ on the 3rd day and $91.46 \%$ on the 4 th day. A $15 \%$ dose ( $6 \mathrm{~g}$ a.i. / ha) caused a markedly higher initial efficacy of $23.30 \%$ as early as $24 \mathrm{~h}$ after administration. The reason for this is most likely the variability of larval age used in different treatments. If younger larval stages are used, the insecticide acted more rapidly. Later, over the next three days of treatment, the efficacy of the $15 \%$ and $30 \%$ doses were equalized. The lowest dose again achieved the weakest results compared to higher doses of spinetoram, but given that only $3 \mathrm{~g}$ a.i./ ha was used, it can be said that the efficacy of $55.38 \%$ on the 4 th day is very satisfactory.

As for azadirachtin, in another study [30], a slower initial efficacy of azadirachtin on L1 stage of CPB was found in a laboratory experiment. Two and three days after the treatment, regardless of doses, the efficacy was $100 \%$. However, this was not the case with L3 larvae as differences in efficacy depending on the doses were found [30], as was the case in our study. The efficacy achieved in another research ranged from $4-63 \%$ on the 7th day, depending on the dose [28]. Such low efficacy should be attributed to extremely low doses of application in the study [28] because the highest dose was only $20 \%$ of the dose recommended for field use, and other doses were even lower. In our laboratory study, higher doses representing $50 \%$ and $25 \%$ of the recommended dose were used, and therefore the efficiencies were expected to be higher. Azadirachtin achieved a gradation in the efficacy over the course of the trial and on the 4th day showed satisfactory effects with an efficiency of $92.92 \%$ (Table 3). Statistically, the efficacy of azadirachtin did not differ 
significantly from that of spinosad and spinetoram. Some authors [31] state that, despite the lower efficacy achieved at lower doses, azadirachtin is recommended in the ecological protection of potatoes against the $\mathrm{CPB}$.

Combinations of lower-dose azadirachtin with the lowest doses of spinosad and spinetoram used in the study were also satisfactorily effective. Slightly lower efficacy was achieved with the combination of azadirachtin and spinosad, at $41.57 \%$ four days after treatment. Given that even the lowest dose of spinosad alone was the least effective, such results are not surprising. The lower dose of spinetoram showed better results $(55.38 \%$ efficacy) than the lowest dose of spinosad (18.66\% efficacy). The addition of spinetoram to azadirachtin achieved an improvement in efficacy to $95.43 \%$ (Table 3 ).

Consumed leaf area was measured during all four days of the experiment, but due to high temperatures, parts of the leaves deteriorated due to rot, which made it impossible to accurately calculate the consumed leaf area on the third and fourth day. The leaf area consumed by CPB larvae differed significantly between all treatments (except the lowest doses of spinosad and spinetoram) and the untreated control in the first two days after application (Table 4). The results obtained confirm the findings of others [30,32], who observed that CPB larvae treated with neem oil showed reduced feeding, resulting in lower leaf damage compared to the control. Because of the antifeedant properties of azadirachtin, it was beneficial to analyze defoliation damage along with efficacy. Others noted that efficacy of azadirachtin treatments is also influenced by defoliation levels, and not just by CPB mortality [33].

Table 4. Potato leaf area consumed $( \pm \mathrm{SE})$ by Colorado potato beetle larvae 24 and $48 \mathrm{~h}$ after treatment.

\begin{tabular}{|c|c|c|c|c|}
\hline \multicolumn{3}{|c|}{ Treatment } & \multicolumn{2}{|c|}{ Consumed Leaf Area $\left(\mathrm{mm}^{2}\right)$} \\
\hline No. & Active Ingredient & Dose a.i. (g/ha) & $24 h^{1}$ & $48 \mathrm{~h}$ \\
\hline 1 & spinosad & 7.2 & $290.82 \pm 22.12$ ef & $462.64 \pm 32.55$ def \\
\hline 2 & spinosad & 3.6 & $173.47 \pm 18.15 \mathrm{f}$ & $273.56 \pm 22.54 \mathrm{f}$ \\
\hline 3 & spinosad & 1.8 & $1255.11 \pm 85.55 \mathrm{ab}$ & $1926.39 \pm 79.55 \mathrm{ab}$ \\
\hline 4 & spinetoram & 12.0 & $568.60 \pm 35.15 \mathrm{~cd}$ & $818.45 \pm 52.45$ cde \\
\hline 5 & spinetoram & 6.0 & $351.40 \pm 29.25 \mathrm{de}$ & $475.48 \pm 39.52 \mathrm{def}$ \\
\hline 6 & spinetoram & 3.0 & $1656.35 \pm 92.32 \mathrm{a}$ & $2292.80 \pm 99.58 \mathrm{a}$ \\
\hline 7 & azadirachtin & 12.5 & $794.15 \pm 52.10 \mathrm{bc}$ & $894.57 \pm 55.54 \mathrm{bcd}$ \\
\hline 8 & azadirachtin & 6.25 & $274.97 \pm 24.13$ ef & $398.82 \pm 29.54$ ef \\
\hline 9 & azadirachtin + spinosad & $6.25+1.8$ & $892.48 \pm 49.10 \mathrm{bc}$ & $1385.64 \pm 82.42 \mathrm{abc}$ \\
\hline 10 & azadirachtin + spinetoram & $6.25+3.0$ & $282.49 \pm 24.12$ ef & $512.25 \pm 52.15 \mathrm{def}$ \\
\hline \multirow[t]{4}{*}{11} & untreated control & $\mathrm{N} / \mathrm{A}$ & $1240.09 \pm 88.12 \mathrm{ab}$ & $2496.00 \pm 110.11 \mathrm{a}$ \\
\hline & Tukey's HSD $p=0.05$ & & 140.059 & 332.723 \\
\hline & Treatment $\mathrm{F}$ & & 36.224 & 20.290 \\
\hline & Treatment Prob (F) & & 0.0001 & 0.0001 \\
\hline
\end{tabular}

\footnotetext{
${ }^{1}$ Prior to analysis, the data were transformed using a $\log (x+1)$ transformation. Means followed by same letter in the same column do not
} significantly differ $(p=0.05$, Tukey's HSD Test).

Since the consumed leaf area on the variants was significantly different compared to control, the efficacy of each variant was calculated based on the preserved leaf area. The efficacy of the insecticide treatments in preserving leaf area (Table 5) followed the observed efficacy on larval mortality, and the insecticide treatments in the first two days after spraying were more efficient in preserving leaf area than in causing larval mortality (Table 3). The treatments protected leaf area with efficacy up to $85.81 \% 24 \mathrm{~h}$ after treatment and up to $88.30 \% 48 \mathrm{~h}$ after treatment (Table 5). The cessation of feeding is often the first visible effect of insecticide action. When assessing the action of insecticides, the data on the initial impact on the diet should be taken into account, although this is not a common practice [26]. 
Table 5. Efficacy (\%) of insecticides $( \pm$ SE) on the preservation of potato leaf area in the first two days of the experiment.

\begin{tabular}{|c|c|c|c|c|}
\hline \multicolumn{3}{|c|}{ Treatment } & \multicolumn{2}{|c|}{$\begin{array}{c}\text { Efficacy of Insecticides (\%) Based on the } \\
\text { Preservation of Leaf Area }\end{array}$} \\
\hline No. & Active Ingredient & Dose a.i. (g/ha) & $24 \mathrm{~h}^{1}$ & $48 \mathrm{~h}$ \\
\hline 1 & spinosad & 7.20 & $76.33 \pm 0.37 \mathrm{a}$ & $80.90 \pm 6.67 \mathrm{a}$ \\
\hline 2 & spinosad & 3.60 & $85.81 \pm 0.27 \mathrm{a}$ & $88.30 \pm 5.41 \mathrm{a}$ \\
\hline 3 & spinosad & 1.80 & $7.68 \pm 2.89 \mathrm{~cd}$ & $23.26 \pm 21.70 \mathrm{de}$ \\
\hline 4 & spinetoram & 12.00 & $52.28 \pm 1.07 \mathrm{ab}$ & $65.37 \pm 13.53 \mathrm{ab}$ \\
\hline 5 & spinetoram & 6.00 & $71.69 \pm 0.42 \mathrm{a}$ & $80.44 \pm 6.54 \mathrm{a}$ \\
\hline 6 & spinetoram & 3.00 & $0.00 \pm 0.00 \mathrm{~d}$ & $12.53 \pm 12.24 \mathrm{e}$ \\
\hline 7 & azadirachtin & 12.50 & $26.91 \pm 3.13 \mathrm{bc}$ & $50.66 \pm 31.67 \mathrm{bc}$ \\
\hline 8 & azadirachtin & 6.25 & $76.45 \pm 0.59 \mathrm{a}$ & $82.69 \pm 8.44 \mathrm{a}$ \\
\hline 9 & azadirachtin + spinosad & $6.25+1.80$ & $15.61 \pm 3.37 c$ & $39.47 \pm 26.00 \mathrm{~cd}$ \\
\hline 10 & azadirachtin + spinetoram & $6.25+3.00$ & $75.29 \pm 0.68 \mathrm{a}$ & $78.13 \pm 9.79 \mathrm{a}$ \\
\hline & Tukey's HSD $p=0.05$ & & 21.250 & 28.833 \\
\hline & Treatment $\mathrm{F}$ & & 29.329 & 27.494 \\
\hline & Treatment Prob (F) & & 0.0001 & 0.0001 \\
\hline
\end{tabular}

${ }^{1}$ Prior to analysis, the data were transformed using $(\sqrt{x}+0.5)$ transformation. Means followed by the same letter on the same column do not significantly differ ( $p=0.05$, Tukey's HSD Test).

Tables 6 and 7 show the results of the $\chi^{2}$ test and the determined effect of the insecticidal combinations, based on the testing of the differences between the achieved and the expected efficiency of the combinations. The same was calculated for both efficacy on CPB larval mortality and efficacy on potato leaf area preservation. The results of the effects of combinations of azadirachtin and spinosad on larval mortality (Table 6) and leaf area preservation (Table 7) in the conducted experiment can be described as antagonism. This result does not coincide with the result of others [12] that investigated the combination of azadirachtin and spinosad $(12.5 \%+33.33 \%$ of the full dose $)$ and stated that an independent synergism was found in the laboratory experiment, although they did not use any calculation methods. The fact that azadirachtin is acting as an antifeedant [30,32] and that spinosad is acting better as stomach than contact poison [34] could explain the established joint action of two insecticides applied in combination. In spite of that the joint action is classified as antagonism and, given into account that very low doses $(25 \%+5 \%$ of the full dose) were applied, the efficacy of combination was significant.

Table 6. Joint action of insecticides on Colorado potato beetle larval mortality.

\begin{tabular}{|c|c|c|c|c|c|c|c|}
\hline Combination & Day & $\mathrm{O}_{\mathrm{b}}$ & $\mathrm{O}_{\mathrm{s}}$ & $\mathbf{E}$ & $\mathbf{O}_{\mathrm{c}}$ & $x^{2}$ & Joint Action ${ }^{2}$ \\
\hline \multirow{4}{*}{$\begin{array}{c}\text { azadirachtin } 6.25 \mathrm{~g} \text { a.i. } / \mathrm{ha}+ \\
\text { spinosad } 1.8 \mathrm{~g} \text { a.i. } / \mathrm{ha} \\
(25 \%+5 \% \text { of } \\
\text { recommended dose })\end{array}$} & 1 & 23.47 & 0.00 & 23.47 & 3.40 & $17.16^{1}$ & \multirow{4}{*}{$\begin{array}{l}\text { antagonism } \\
\text { antagonism } \\
\text { antagonism } \\
\text { antagonism }\end{array}$} \\
\hline & 2 & 38.00 & 6.00 & 41.72 & 16.00 & $15.86^{1}$ & \\
\hline & 3 & 60.00 & 21.11 & 68.44 & 37.78 & $13.74^{1}$ & \\
\hline & 4 & 92.92 & 18.66 & 94.24 & 41.57 & $29.44^{1}$ & \\
\hline \multirow{4}{*}{$\begin{array}{c}\text { azadirachtin } 6.25 \mathrm{~g} \text { a.i. } / \mathrm{ha}+ \\
\text { spinetoram } 3.0 \mathrm{~g} \text { a.i. } / \mathrm{ha} \\
(25 \%+7.5 \% \text { of } \\
\text { recommended dose })\end{array}$} & 1 & 23.47 & 1.92 & 24.94 & 23.30 & 0.11 & \multirow{4}{*}{$\begin{array}{l}\text { independent } \\
\text { synergism } \\
\text { independent } \\
\text { synergism } \\
\text { independent } \\
\text { synergism } \\
\text { independent } \\
\text { synergism }\end{array}$} \\
\hline & 2 & 38.00 & 30.00 & 56.60 & 48.00 & 1.31 & \\
\hline & 3 & 60.00 & 48.89 & 79.56 & 73.33 & 0.49 & \\
\hline & 4 & 92.92 & 55.38 & 96.84 & 95.43 & 0.02 & \\
\hline
\end{tabular}

${ }^{1} \chi^{2}$ values are significantly different comparing to $\chi^{2} \mathrm{tbl}_{(p=0.05, \mathrm{df}=1)}=3.84 .{ }^{2}$ If $\mathrm{O}_{\mathrm{c}}>\mathrm{E}$ the joint action is described as synergism, if $\mathrm{O}_{\mathrm{c}}<\mathrm{E}$ the joint action is described as antagonism, if the obtained $\chi^{2}$ does not differ significantly from the tabular one, the effect of the combination is an independent synergism. 
Table 7. Joint action of insecticides based on potato leaf area preservation data.

\begin{tabular}{cccccccc}
\hline Combination & Day & $\mathbf{O}_{\mathbf{b}}$ & $\mathbf{O}_{\mathbf{s}}$ & $\mathbf{E}$ & $\mathbf{O}_{\mathbf{c}}$ & $\chi^{2}$ & Joint Action $^{2}$ \\
\hline $\begin{array}{c}\text { azadirachtin 6.25 g a.i./ha }+ \\
\text { spinosad 1.8 g a.i./ha }\end{array}$ & 1 & 76.45 & 7.68 & 78.26 & 15.61 & $50.15^{1}$ & antagonism \\
$(25 \%+5 \%$ of recommended dose $)$ & 2 & 82.69 & 23.26 & 86.72 & 39.47 & $25.74^{1}$ & antagonism \\
\hline $\begin{array}{c}\text { azadirachtin 6.25 g a.i./ha }+ \\
\text { spinetoram 3.0 g a.i./ha }\end{array}$ & 1 & 76.45 & 0.00 & 76.45 & 75.29 & 0.02 & $\begin{array}{c}\text { independent } \\
\text { synergism } \\
\text { independent } \\
\text { synergism }\end{array}$ \\
\hline
\end{tabular}

${ }^{1} \chi^{2}$ values are significantly different comparing to $\chi^{2} \mathrm{tbl}(p=0.05, \mathrm{df}=1)=3.84 .{ }^{2}$ If $\mathrm{O}_{\mathrm{c}}>\mathrm{E}$ the joint action is described as synergism, if $\mathrm{O}_{\mathrm{c}}<\mathrm{E}$ the joint action is described as antagonism, if the obtained $\chi 2$ does not differ significantly from the tabular one, the effect of the combination is an independent synergism.

In contrast to spinosad, the effect of combinations of azadirachtin and spinetoram on larval mortality and leaf area preservation in the experiment can be described as independent synergism. The results obtained can confirm that the insecticides used have different modes of action and act independently in the mixture. The result of the joint action of insecticides in the case of different modes of action is generally described as independent synergism [35], which in this case was also proven by our results between azadirachtin and spinetoram (Tables 6 and 7).

\subsection{Field Trial}

The results obtained in the laboratory study were verified in the study in field conditions due to the fact that in the field the effectiveness of insecticides is influenced by a large number of factors that are not present in the laboratory [26].

All insecticidal treatments reduced the average number of larvae per plot when compared to the untreated control, with significant reductions seen on all treatments except for the $10 \%$ dosage of spinosad and spinetoram, where only moderate reductions were seen (Table 8). Overall, the half and full doses of spinosad showed the highest efficacy rates with residual activity of 10-21 days, depending on the treatment.

Table 8. Efficacy (\%) of insecticide treatments ( \pm SE) on Colorado potato beetle larvae in the field trial, Zagreb, 2019.

\begin{tabular}{|c|c|c|c|c|c|c|c|}
\hline \multirow{2}{*}{ Treatment } & \multirow{2}{*}{$\begin{array}{c}\text { Dose } \\
\text { (g a.i./ha) }\end{array}$} & \multicolumn{6}{|c|}{ Efficacy (\%) on Days after Treatment } \\
\hline & & 2 & 5 & 7 & 10 & 14 & 21 \\
\hline spinosad & 36.0 & $98.74 \pm 6.76 \mathrm{a}$ & $92.65 \pm 23.55 \mathrm{ab}$ & $90.16 \pm 15.45 \mathrm{a}$ & $88.18 \pm 12.16$ & $72.98 \pm 18.00$ & $72.51 \pm 24.31$ \\
\hline spinosad & 18.0 & $97.24 \pm 6.86 \mathrm{ab}$ & $98.93 \pm 6.94 \mathrm{a}$ & $96.80 \pm 0.92 \mathrm{a}$ & $94.45 \pm 11.86$ & $68.18 \pm 27.06$ & $42.33 \pm 39.35$ \\
\hline spinosad & 3.6 & $68.39 \pm 5.66 \mathrm{ab}$ & $30.09 \pm 28.89 \mathrm{abc}$ & $64.89 \pm 14.70 \mathrm{ab}$ & $60.64 \pm 21.25$ & $75.00 \pm 18.11$ & $79.54 \pm 15.85$ \\
\hline spinetoram & 36.0 & $87.13 \pm 15.11 \mathrm{ab}$ & $85.93 \pm 21.15 \mathrm{ab}$ & $88.79 \pm 17.24 \mathrm{a}$ & $94.16 \pm 4.54$ & $81.82 \pm 23.15$ & $67.12 \pm 27.30$ \\
\hline spinetoram & 18.0 & $84.92 \pm 18.90 \mathrm{ab}$ & $80.53 \pm 14.55 \mathrm{abc}$ & $89.24 \pm 7.26 \mathrm{a}$ & $83.00 \pm 17.90$ & $70.96 \pm 28.66$ & $61.99 \pm 23.64$ \\
\hline spinetoram & 3.6 & $51.87 \pm 36.53 \mathrm{ab}$ & $23.60 \pm 14.19 \mathrm{bc}$ & $40.27 \pm 22.80 b$ & $60.50 \pm 19.77$ & $67.16 \pm 30.58$ & $37.73 \pm 50.19$ \\
\hline azadirachtin & 25.0 & $46.68 \pm 19.01 \mathrm{ab}$ & $72.00 \pm 8.51 \mathrm{abc}$ & $65.45 \pm 25.22 \mathrm{ab}$ & $71.72 \pm 15.25$ & $77.27 \pm 15.83$ & $84.37 \pm 9.42$ \\
\hline azadirachtin & 12.5 & $38.62 \pm 13.37 b$ & $18.95 \pm 7.03 \mathrm{bc}$ & $49.93 \pm 6.09 \mathrm{ab}$ & $63.01 \pm 5.39$ & $54.23 \pm 18.93$ & $56.11 \pm 42.69$ \\
\hline $\begin{array}{l}\text { azadirachtin }+ \\
\text { spinosad }\end{array}$ & $12.5+3.6$ & $58.17 \pm 5.86 \mathrm{ab}$ & $77.18 \pm 9.93 \mathrm{abc}$ & $81.46 \pm 15.07 \mathrm{ab}$ & $75.89 \pm 20.49$ & $71.21 \pm 17.70$ & $64.96 \pm 23.37$ \\
\hline $\begin{array}{l}\text { azadirachtin + } \\
\text { spinetoram }\end{array}$ & $12.5+3.6$ & $51.95 \pm 18.72 \mathrm{ab}$ & $78.64 \pm 15.37 \mathrm{abc}$ & $71.40 \pm 34.32 \mathrm{ab}$ & $61.53 \pm 34.82$ & $70.45 \pm 27.12$ & $47.98 \pm 21.32$ \\
\hline \multicolumn{2}{|c|}{ Tukey's HSD $p=0.05$} & 59.312 & 54.675 & 48.052 & $\mathrm{~ns}$ & ns & ns \\
\hline \multicolumn{2}{|c|}{ Treatment F } & 2.501 & 4.369 & 3.445 & 1.114 & 0.515 & 1.409 \\
\hline \multicolumn{2}{|c|}{ Treatment Prob (F) } & 0.0421 & 0.0026 & 0.0069 & 0.39014 & 0.8498 & 0.2391 \\
\hline
\end{tabular}

Means followed by same letter in the same column do not significantly differ ( $p=0.05$, Tukey's HSD Test).

For the series of spinosad treatments, both the $50 \%$ and $100 \%$ treatments showed very high efficacy results, $94-99 \%$ and $88-99 \%$, respectively, with 10 days of residual activity, after which the efficacy rates began to drop off. For the $10 \%$ treatment, low to moderate efficacy was observed, with a peak of $80 \%$ at 21 days after treatment (Table 8). This is consistent with results from other studies [12,34,36,37]. The $50 \%$ dose achieved consistently higher efficacy results than the $100 \%$ dose starting from 5 days after treatment. It should be 
noted that one of the replicates of the $100 \%$ spinosad treatment had significantly higher larvae counts compared to the other three replicates. This is possibly due to the fact that spinosad does not possess ovicidal effects towards CPB eggs [38], therefore it is possible a cluster of eggs hatched shortly after treatment, increasing the larvae count for this plot. Efficacy results would likely be calculated at higher values for the $100 \%$ treatment had this data not skewed the results. If this was the case, then efficacy of the $100 \%$ treatment would be expected to be equivalent or higher than the $50 \%$ treatment. Efficacy dropped significantly around day 14 for both treatments (50\% and 100\%), indicating low residual activity. This is consistent with results found by [12], who also noticed efficacies drop around day 10 or 14, depending on the experimental year. The opposite result was seen with the treatment of $10 \%$ of recommended dose. Efficacy appeared to increase over time with a maximum efficacy of $79.54 \%$ reached at day 21 after treatment. It is suspected that this result was caused by early defoliation on these treatment plots, as heavy defoliation was witnessed in these plots towards the middle and end of the trial.

The 50\% and 100\% spinetoram treatments provided high efficacy, though not at levels seen in the spinosad plots. The $100 \%$ treatment peaked at $94.16 \%$ efficacy 10 days after the treatment and dropped significantly in the third week of the trial. The 50\% treatment peaked at $89.24 \% 7$ days after the trial began (Table 8). While the efficacies were still relatively high, they did not reach the levels achieved by the spinosad treatments, suggesting spinosad is more suited for CPB control than spinetoram. Though the two active ingredients function with the same mode of action, it is possible that the spinosyns $A$ and D found in spinosad induce mortality at higher rates than spinosyns $\mathrm{J}$ and $\mathrm{L}$ found in spinetoram. The $10 \%$ treatment provided the least control, showing that a clear dose response was present. The 10\% treatment showed the highest efficacies around 10-14 days after treatment, with a maximum efficacy of $67.16 \% 14$ days after treatment, providing only low control levels.

The efficacy of azadirachtin was clearly higher for the $100 \%$ dosage compared to the $50 \%$ of full dosage. The efficacy of a full dose of azadirachtin peaked at $84.37 \%, 21$ days after treatment and the efficacy of the half dose peaked at $63.01 \%, 10$ days after treatment (Table 8). This indicates that the lower dosing has shorter residual activity, as well as lower efficacy. These efficacy levels match other studies conducted, which obtained efficacy levels between 53.5-88\% [12,37]. There are conflicting results amongst the literature as to the expected residual activity of treatments of azadirachtin. One study found the residual activity lasted only around 7 days [12], which would require multiple treatments throughout the potato growing season. Our results showed the highest efficacy from the full dose treatment at 3 weeks after treatment, suggesting the known antifeedant properties of azadirachtin played a role in eventual mortality of the CPB larvae. Another study [39] also claimed a single full dose treatment of azadirachtin was sufficient for control, which is more in line with our results.

For the combined treatment of a 50\% dose of azadirachtin and a $10 \%$ dose of spinosad, the efficacy was higher than the individual treatments from 5-10 days after treatment, with the peak efficacy reaching $81.46 \%$ at day 7 after treatment (Table 8 ). Starting with day 14 until day 21 , the $10 \%$ spinosad treatment appeared to outperform the combinational treatment, achieving an efficacy $15 \%$ greater than the combined treatment on day 21 . This could be due to the previously mentioned explanation of high defoliation on the $10 \%$ spinosad treatment plots. The combined treatment really outperforms the individual treatments on day 5 . The efficacy of the combined treatment was $77.18 \%$ and the sum of the individual treatments only totaled $49.04 \%$. It appears this combination provides a synergism which boosts efficacy to a level higher than the sum of individual treatments around day 5. The same result was not witnessed for any of the other efficacy calculations, even on days 7 and 10 when the combined treatment offered superior control than either one of the individual treatments, but still fell short of exceeding the sum of individual treatment efficacies. 
The combination of a 50\% dose of azadirachtin and a $10 \%$ dose of spinetoram did not perform as well as the combination of azadirachtin with spinosad, achieving only moderate efficacy results, with a peak of $78.64 \%$ on day 5 and providing residual activity until around day 14 (Table 8). A similar result was witnessed (with the spinosad and azadirachtin combination) on day 5 , that the combined treatment's efficacy far exceeded the sum of individual efficacies $(42.55 \%)$. Again, this was the only time this was witnessed. On days 7, 10 and 14, the combined treatment provided superior control to either one of the individual treatments but did not provide the synergistic effect seen on day 5 .

The effect of both combinations of azadirachtin and spinosad or spinetoram on larval mortality in the field trial varied (Table 9). At first (day 2) the effect of both combinations can be described as antagonism, which can be attributed to azadirachtin acting as an antifeedant [30,32] and spinosad or spinetoram acting better as stomach than contact poison [34]. Synergistic effect was seen on day 5 , when achieved efficacy was higher than expected. Seven days after treatment, the effect of both combinations on larval mortality can be described as independent synergism, suggesting that the insecticides used have different modes of action and act independently in the mixture.

Table 9. Joint action of insecticides on Colorado potato beetle larval mortality determined in the field trial, Zagreb, 2019.

\begin{tabular}{|c|c|c|c|c|c|c|c|}
\hline Combination & Day & $\mathrm{O}_{\mathrm{b}}$ & $\mathrm{O}_{\mathrm{s}}$ & $\mathbf{E}$ & $\mathrm{O}_{\mathrm{c}}$ & $x^{2}$ & Joint Action ${ }^{2}$ \\
\hline \multirow{3}{*}{$\begin{array}{c}\text { azadirachtin } 12.5 \mathrm{~g} \text { a.i. } / \mathrm{ha}+ \\
\text { spinosad } 3.6 \mathrm{~g} \text { a.i. } / \text { ha } \\
(50 \%+10 \% \text { of recommended dose })\end{array}$} & 2 & 38.62 & 68.39 & 100 & 58.17 & $17.50^{1}$ & \multirow{3}{*}{$\begin{array}{l}\text { antagonism } \\
\text { synergism } \\
\text { independent } \\
\text { synergism }\end{array}$} \\
\hline & 5 & 18.95 & 30.09 & 48.85 & 77.18 & $16.43^{1}$ & \\
\hline & 7 & 49.93 & 64.89 & 100 & 81.46 & 3.44 & \\
\hline \multirow{3}{*}{$\begin{array}{c}\text { azadirachtin } 12.5 \mathrm{~g} \text { a.i. } / \mathrm{ha}+ \\
\text { spinetoram } 3.6 \mathrm{~g} \text { a.i. } / \mathrm{ha} \\
(50 \%+10 \% \text { of recommended dose })\end{array}$} & 2 & 38.62 & 51.87 & 90.10 & 51.95 & $16.16^{1}$ & \multirow{3}{*}{$\begin{array}{l}\text { antagonism } \\
\text { synergism } \\
\text { independent } \\
\text { synergism }\end{array}$} \\
\hline & 5 & 18.95 & 23.60 & 42.36 & 78.64 & $31.07^{1}$ & \\
\hline & 7 & 49.93 & 40.27 & 89.70 & 71.40 & 3.73 & \\
\hline
\end{tabular}

${ }^{1} \chi^{2}$ values are significantly different comparing to $\chi^{2} \mathrm{tbl}(p=0.05, \mathrm{df}=1)=3.84 .{ }^{2}$ If $\mathrm{O}_{\mathrm{c}}>\mathrm{E}$ the joint action is described as synergism, if $\mathrm{O}_{\mathrm{c}}<\mathrm{E}$ the joint action is described as antagonism, if the obtained $\chi^{2}$ does not differ significantly from the tabular one, the effect of the combination is an independent synergism.

The results show that the addition of low doses of spinosad or spinetoram to half doses of azadirachtin improved the field efficacy of azadirachtin alone between days 5-14 after treatments. As the only major improvement in efficacy from the combinational treatment was seen on day 5 after treatment, it is unclear if the resultant efficacy of combination was simply from the presence of spinosyns in the combination, or if it was due to some synergistic effect between the spinosyns and azadirachtin. A possible impairment of the combination of azadirachtin and spinosyns was the fact that azadirachtin acts as an antifeedant and spinosyns are highly active via ingestion, therefore the antifeedant result from azadirachtin would halt the potential impact of spinosyn ingestion [12]. The author recommends further studies on these combinations, specifically the addition of higher doses of spinosyn containing products with azadirachtin, perhaps around the levels of $20-30 \%$ of recommended doses with the same $50 \%$ dose of azadirachtin. If high efficacy results were seen with these dosing rates, this could be a viable option for implementation into an IPM program for CPB control, while also achieving desirable economic results in the form of less active ingredients used. The results of this study suggest that the combination of $50 \%$ azadirachtin with $10 \%$ spinosad provide moderate efficacy, and with short residual effects. More effective are the half doses of spinosad or spinetoram, which provided moderate to high efficacy. These treatments could easily be incorporated into an IPM system while also providing a satisfactory economic outcome. Others also made the same recommendation [12], suggesting that the manufacturer's recommended dosage is higher than necessary to achieve CPB control. Reducing the dosing will also help to prevent or delay populations from developing resistance to the active ingredients spinosyns. According to Arthropod Pesticide Resistance Database (APRD), several cases of spinosad resistance in CPB have been reported, including field 
evolved resistance [40-42], emphasizing the need to find other solutions, such as the use of reduced doses of insecticides or combinations of such reduced doses.

The modes of action of spinosyns and azadirachtin are different from each other, which allows for slowed development of resistance when used in combination. Spinosyns act by allosterically binding to the nicotinic acetylcholine receptor (nAChR) causing hyperexcitation of the nervous system [29]. The specific molecular mode of action for azadirachtin is still unknown but there are several symptoms of exposure including multiple mechanisms of antifeedancy, growth regulation and sterility [30]; none of which are similar to the mode of action of spinosyns. This method of combining treatments with unique modes of action is an important tool when considering any IPM strategy. While a result of synergism would be the most desired outcome when considering combinational treatments, even the result of increased efficacy of azadirachtin with small additions of spinosyns can be considered a positive outcome.

\section{Conclusions}

If the application of low-dose insecticide combinations has fulfilled environmental and economic aspects, even in cases of established independent synergism, they should be used in pest control [12]. Therefore, by combining spinetoram and azadirachtin, satisfactory effects on Colorado potato beetle larvae could be achieved while using significantly lower doses of insecticides. This contributes to less environmental pollution (even though these insecticides are considered environmentally friendly) and lower control costs. The application of such combinations could significantly contribute to the preservation of the environment and the achievement of sustainable use of pesticides. The need for new and novel treatment methods for $\mathrm{CPB}$ control is more important now than ever, especially with the latest development of resistance to neonicotinoids. Active ingredients such as spinosyns and azadirachtin are highly biodegradable, offer low mammalian toxicity and pose little threat to beneficial organisms in the field. Overall, they are far more ecologically sound treatment options than classical synthetic insecticides and should be considered when developing any IPM strategy to tackle CPB infestations. Despite the fact that our results show good efficacy, sub-dosing may enhance development of resistance as it allows survival of heterozygous alleles $(\mathrm{S} / \mathrm{R})$ and gradual/faster resistance establishment. Therefore, the possibility of resistance development should be taken into account when applying sub-doses in practice. To minimize this, insecticides with different modes of action should be used in such combinations, and different combinations (different doses and different insecticides) should be alternated to avoid resistance development.

Author Contributions: Conceptualization, R.B.; Funding acquisition, R.B.; Investigation, J.O., I.J., Z.D., M.K.B. and M.Č.; Methodology, R.B.; Project administration, M.Č.; Resources, R.B.; Supervision, R.B. and M.Č.; Writing—original draft, M.K.B. and M.Č.; Writing—review and editing, R.B. and Z.D. All authors have read and agreed to the published version of the manuscript.

Funding: This research was funded by the Croatian Science Foundation projects "Monitoring of Insect Pest Resistance: Novel Approach for Detection, and Effective Resistance Management Strategies (MONPERES)", grant number IP-2016-06-7458; and "Young researchers' career development project training of new doctoral students", grant number DOK-01-2018.

Institutional Review Board Statement: Not applicable.

Informed Consent Statement: Not applicable.

Data Availability Statement: The data presented in this study are available on request from the corresponding author.

Acknowledgments: The authors thank all colleagues and students who helped in the implementation of the experiment in the field.

Conflicts of Interest: The authors declare no conflict of interest. The funders had no role in the design of the study; in the collection, analyses, or interpretation of data; in the writing of the manuscript, or in the decision to publish the results. 


\section{References}

1. FAOSTAT. Available online: www.fao.org/faostat/en/\#data/FBS (accessed on 11 May 2021).

2. FAO. Why Potato? Available online: www.fao.org/potato-2008/en/aboutiyp/index.html (accessed on 6 March 2019).

3. Casagrande, R.A. The Colorado Potato Beetle: 125 Years of Mismanagement. Bull. Èntomol. Soc. Am. 1987, 33, 142-150. [CrossRef]

4. Alyokhin, A.; Baker, M.; Mota-Sanchez, D.; Dively, G.; Grafius, E. Colorado Potato Beetle Resistance to Insecticides. Am. J. Potato Res. 2008, 85, 395-413. [CrossRef]

5. Alyokhin, A. Colorado Potato Beetle Management on Potatoes: Current Challenges and Future Prospects. Fruit Veg. Cereal Sci. Biotech. 2009, 3, 10-19.

6. Alyokhin, A.; Udalov, M.; Benkovskaya, G. Insect Pests of Potato: Global Perspectives on Biology and Management, 1st ed.; Academic Press: Oxford, UK, 2013; pp. 11-22.

7. Cingel, A.; Savić, J.; Lazarević, J.; Ćosić, T.; Raspor, M.; Smigocki, A.; Ninković, S. Extraordinary Adaptive Plasticity of Colorado Potato Beetle: "Ten-Striped Spearman" in the Era of Biotechnological Warfare. Int. J. Mol. Sci. 2016, 17, 1538. [CrossRef] [PubMed]

8. Worner, S.P. Ecoclimatic Assessment of Potential Establishment of Exotic Pests. J. Econ. Ėntomol. 1988, 81, 973-983. [CrossRef]

9. Weber, D. Colorado beetle: Pest on the move. Pestic. Outlook 2003, 14, 256-259. [CrossRef]

10. Balaško, M.K.; Mikac, K.M.; Bažok, R.; Lemic, D. Modern Techniques in Colorado Potato Beetle (Leptinotarsa decemlineata Say) Control and Resistance Management: History Review and Future Perspectives. Insects 2020, 11, 581. [CrossRef] [PubMed]

11. Göldel, B.; Lemic, D.; Bažok, R. Alternatives to Synthetic Insecticides in the Control of the Colorado Potato Beetle (Leptinotarsa decemlineata Say) and Their Environmental Benefits. Agriculture 2020, 10, 611. [CrossRef]

12. Barčić, J.I.; Bažok, R.; Bezjak, S.; Čuljak, T.G. Combinations of several insecticides used for integrated control of Colorado potato beetle (Leptinotarsa decemlineata, Say., Coleoptera: Chrysomelidae). J. Pest Sci. 2006, 79, 223-232. [CrossRef]

13. IRAC. Susceptibility Test Method No: 007. Version 3.1. July 2014. Available online: https://irac-online.org/methods/leaf-eatinglepidoptera-coleoptera-larvae/ (accessed on 6 May 2021).

14. Kovačević, Ž. Applied Entomology; Poljoprivredni nakladni zavod: Zagreb, Croatia, 1961. (In Croatian)

15. Thabet, A.F.; Boraei, H.A.; Galal, O.A.; El-Samahy, M.F.M.; Mousa, K.M.; Zhang, Y.Z.; Tuda, M.; Helmy, E.A.; Wen, J.; Nozaki, T. Silica nanoparticles as pesticide against insects of different feeding types and their non-target attraction of predators. Sci. Rep. 2021, 11, 14484. [CrossRef]

16. Attique, M.N.R.; Khaliq, A.; Sayyed, A.H. Could resistance to insecticides in Plutella xylostella (Lep., Plutellidae) be overcome by insecticide mixtures? J. Appl. Ėntomol. 2006, 130, 122-127. [CrossRef]

17. Pope, C. Chemical Interactions. In Encyclopedia of Toxicology; Elsevier BV: Amsterdam, The Netherlands, 2014 ; pp. 793-794.

18. Roush, R. Occurrence, genetics and management of insecticide resistance. Parasitol. Today 1993, 9, 174-179. [CrossRef]

19. Curtis, C.F. Theoretical models of the use of insecticide mixtures for the management of resistance. Bull. Èntomol. Res. 1985, 75, 259-266. [CrossRef]

20. Martin, T.; Ochou, G.O.; Hala-N'Klo, F.; Vassal, J.M.; Vaissayre, M. Pyrethroid resistance in the cotton bollworm, Helicoverpa armigera (Hübner), in West Africa. Pest Manag. Sci. 2000, 56, 549-554. [CrossRef]

21. Helps, J.; Paveley, N.; Bosch, F.V.D. Identifying circumstances under which high insecticide dose increases or decreases resistance selection. J. Theor. Biol. 2017, 428, 153-167. [CrossRef] [PubMed]

22. EPPO. EPPO Standard PP1/012(4)—Efficacy Evaluation of Insecticides, Leptinotarsa decemlineata; European and Mediterranean Plant Protection Organization: Paris, France, 2008.

23. Püntener, W. Manual for Field Trials in Plant Protection, 2nd ed.; Ciba-Geigy Limited: Basle, Switzerland, 1981.

24. Abbott, W.S. A Method of Computing the Effectiveness of an Insecticide. J. Econ. Èntomol. 1925, 18, 265-267. [CrossRef]

25. GDM Solutions, Inc. ARM 2021.0 software, Feb 14 2021; GDM Solutions, Inc.: Brookings, SD, USA.

26. Dobrinčić, R. Investigations of Interactions Between different groups of Insecticides in the Control of the Colorado Potato Beetle (Leptinotarsa decemlineata Say). Agric. Conspec. Sci. 1996, 61, 23-43. (In Croatian)

27. Dobrinčić, R.; Igrc Barčić, J. Investigations of classical combinations and new generations of insecticides for the control of the Colorado potato beetle (Leptinotarsa decemlineata Say, Coleoptera: Chrysomelidae). Fragm. Phytomed. 1998, 26, 53-66. (In Croatian)

28. Bažok, R.; Đurek, I.; Igrc Barčić, J.; Gotlin Čuljak, T. Joint action of ecologically acceptable insecticides for the Colorado Potato Beetle (Leptinotarsa decemlineata Say, Coleoptera: Chrysomelidae) control. Fragm. Phytomed. 2008, 30, 47-63. (In Croatian)

29. Čačija, M.; Bažok, R.; Lemić, D.; Mrganić, M.; Virić Gašparić, H.; Drmić, Z. Spinosyns-naturally derived insecticides. Fragm. Phytomed. 2018, 32, 43-60. (In Croatian)

30. Kadoić Balaško, M.; Neral, K.; Nađ, B.; Bažok, R.; Drmić, Z.; Čačija, M. Azadirachtin efficacy in Colorado potato beetle and Western flower thrips control. Rom. Agric. Res. 2021, 38, 36.

31. Bezjak, S.; Igrc Barčić, J.; Bažok, R. Efficacy of botanical insecticides in Colorado potato beetle (Leptinotarsa decemlineata, Say., Coleoptera: Chrysomelidae) control. Fragm. Phytomed. 2006, 29, 13-24. (In Croatian)

32. Kovaříková, K.; Pavela, R. United Forces of Botanical Oils: Efficacy of Neem and Karanja Oil against Colorado Potato Beetle under Laboratory Conditions. Plants 2019, 8, 608. [CrossRef]

33. Schrod, J.; Basedow, T.; Langenbruch, G.A. Untersuchungen zur Bionomie und zur biologischen Bekämpfung des Kartoffelkäfers (Leptinotarsa decemlineata Say, Col., Chrysomelidae) an zwei Standorten in Südhessen (BRD). J. Appl. Ėntomol. 1996, 120, 619-626. [CrossRef] 
34. Bret, B.L.; Larson, L.L.; Schoonover, J.R.; Sparks, T.C.; Thompson, G.D. Biological properties of spinosad. Down Earth 1997, 52, 6-13.

35. Benz, G. Synergism of microorganisms and chemical insecticides. In Microbial Control of Insects and Mites; Burges, H.G., Hussey, N.W., Eds.; Academic Press: New York, NY, USA, 1971; pp. 327-355.

36. Igrc, J.; Barčič, J.; Dobrinčič, R.; Maceljski, M. Effect of insecticides on the Colorado potato beetles resistant to OP, OC and P insecticides. J. Pest Sci. 1999, 72, 76-80. [CrossRef]

37. Marcic, D.; Peric, P. Field evaluation of natural and synthetic insecticides against Leptinotarsa decemlineata Say. Acta Hortic. 2009, 830, 391-396. [CrossRef]

38. Sharif, M.; Hejazi, M. Toxicity of spinosad against developmental stages of Colorado potato beetle, Leptinotarsa decemlineata Say (Coleoptera: Chrysomelidae). J. Crop Prot. 2014, 3, 129-136.

39. Baumgart, M.; Brocke, K.; Crow, M.H. Control of the Colorado potato beetle (Leptinotarsa decemlineata Say) in organic gardening systems with Bacillus thuringiensis var. san diego (M-One) and new products from the neem tree (NeemAzal-F and AlignTM). In Practice Oriented Results on Use and Production of Neem-Ingredients and Pheromones, Proceedings of 5th Workshop, Wetzlar, Germany, 22-25 January 1996; Kleeberg, H., Zebitz, C.P.W., Eds.; Druck \& Graphic: Giessen, Germany, 1997; pp. 67-73.

40. Mota-Sanchez, D.; Hollingworth, R.M.; Grafius, E.J.; Moyer, D.D. Resistance and cross-resistance to neonicotinoid in-secticides and spinosad in the Colorado potato beetle, Leptinotarsa decemlineata (Say) (Coleoptera: Chrysomelidae). Pest Manag. Sci. 2006, 62, 30-37. [CrossRef]

41. Klein, C.; Baker, M.; Alyokhin, A.; Mota-Sanchez, D. Geographic Variation in Dominance of Spinosad Resistance in Colorado Potato Beetles (Coleoptera: Chrysomelidae). J. Econ. Ėntomol. 2021, 114, 320-325. [CrossRef] [PubMed]

42. Schnaars-Uvino, K.; Baker, M.B. High-level field-evolved resistance to spinosad in Colorado potato beetle, Leptinotarsa decemlineata, in organically managed fields. Pest Manag. Sci. 2021, 77, 4393-4399. [CrossRef] [PubMed] 